\title{
A Tyr368His RPE65 founder mutation is associated with variable expression and progression of early onset retinal dystrophy in 10 families of a genetically isolated population
}

S Yzer, L I van den Born, J Schuil, H Y Kroes, M M van Genderen, F N Boonstra, B van den Helm, H G Brunner, R K Koenekoop, F P M Cremers

A utosomal recessive retinal dystrophies cause visual impairment in approximately 1 in 4000 individuals worldwide. ${ }^{1}$ The non-syndromic forms are highly heterogeneous and can be classified into clinical subgroups, the most frequent ones being retinitis pigmentosa, cone and cone-rod dystrophies, and Leber congenital amaurosis (LCA). LCA represents the most severe phenotype with an onset of symptoms before the age of six months, visual acuity below 20/400, a searching nystagmus, sluggish pupillary reactions, and a non-detectable electroretinogram (ERG). Visual fields are usually not measurable. ${ }^{1}$ Photophobia is only occasionally reported in LCA. $^{2}$ Patients with juvenile and early onset retinitis pigmentosa present with night blindness in early childhood, usually before the age of two years. They do not show searching nystagmus ${ }^{3}$ and have a relatively well preserved macular function. Central vision is often lost in the second or third decade of life. ${ }^{4}$

The cloning of more than 20 genes allows the molecular characterisation of approximately $50 \%$ of the autosomal recessive inherited retinal dystrophy cases (http:// www.sph.uth.tmc.edu/Retnet ${ }^{5}{ }^{6}$ ). To establish a useful clinical prognosis for patients a well defined genotype-phenotype correlation is required.

Although the general population in the Netherlands is relatively outbred, there are a few examples of autosomal recessive diseases caused by Dutch founder mutations. Batten disease was found to be due to identity-by-descent in a highly inbred family. ${ }^{7}$ A frequent LDL receptor mutation originating from Dutch 17th century settlers causes familial hypercholesterolaemia in South Africa and Canada. ${ }^{8}$ The RP12 locus was mapped through linkage analysis in a genetic isolate from the northwest of the Netherlands, ${ }^{9}$ which was followed by the cloning of the underlying gene, $C R B 1 .^{10}$

In 1959 Schappert-Kimmijser et al described an isolated Dutch population living on a former island with a relatively high frequency of LCA. ${ }^{11}$ In 1637 this community suffered from the plague, which killed half the population. After the island was connected to the mainland in 1941, the 4000 residents could be regarded as descendants of at most 150 ancestors. Since then, the population size has quadrupled, mostly through endogamous marriages.

We re-evaluated this population and established a new multigenerational pedigree, consisting of 10 nuclear families with congenital retinal dystrophy. We undertook detailed clinical and molecular studies and identified two RPE65 mutations, one of which represents a frequent founder mutation in the genetic isolate.

\section{METHODS}

Fourteen patients with congenital retinal dystrophy, 25 of their non-affected siblings, and 19 parents were asked to

\section{Key points}

- The ophthalmological characteristics and molecular cause of retinal dystrophy were investigated in 14 patients from 10 families from a genetic isolate in the Netherlands.

- Based on the phenotype-consisting of night blindness, nystagmus, variable progression of visual acuity, unrecordable electroretinogram (ERG) responses in most patients in early childhood, and relatively well preserved peripheral vision-the involvement of the RPE65 gene was hypothesised.

- In nine families, patients were found to be homozygous for a RPE65 Tyr368His mutation; in one family the patient was compound heterozygous for the RPE65 Tyr 368 His and IVS1 $+5 \mathrm{~g} \rightarrow$ a mutations.

- Three heterozygous carriers were identified in 96 healthy controls from this population, resulting in a significant risk of blindness in offspring of patients, their heterozygous siblings, and other heterozygous individuals of the genetic isolate.

participate in the study. The study protocol adhered to the regulations of the Declaration of Helsinki.

\section{Clinical analysis}

Parents and patients were questioned about pregnancy, delivery, the age of onset of symptoms, night blindness, photophobia, and birth defects. Ophthalmic examinations were done by one of us (JS, FNB, or MMvG). All children were seen between 1978 and the present. The mean follow up period was nine years and ranged from two to 15 years.

Ophthalmic examinations included best corrected visual acuity with age adapted functional tests, such as Teller acuity cards in the preverbal period and the Lea Hyvärinen test for children who were able to match or name pictures. From the age of six years Snellen charts were used. Objective refractive error was measured after cycloplegia. Pupillary reactions were tested and nystagmus and photophobia were evaluated. Night blindness was tested by observing the patients' behaviour in a dim lighted room. The anterior segment was examined using a slit lamp, followed by dilated fundoscopy. Kinetic visual fields were measured with Tübinger perimetry (with a 10 apostilbs background) in 13 patients. Electroretinographic recordings were made in all patients but one, and were done at two university hospitals. Colour vision was tested with the Ishihara test for colour blindness, Hardy Rand Rittler (H-R-R) charts, and Lanthony's saturated D-15 test. Dark adaptometry was undertaken in three 
patients with the Goldmann-Weekers dark adaptometer. Fundus photographs were taken with a Topcon retinal camera, model TRC-F.

\section{Molecular analysis}

Venous blood was collected and DNA was extracted using a previously described protocol. ${ }^{12}$ DNA was analysed using the highly polymorphic DNA marker D1S2803 (AFMB361YD5) located 2.5 kilobases (kb) proximal to the RPE65 gene and DIS2895 (AFMA099WC1), located approximately 2.7 megabases ( $\mathrm{Mb})$ proximal to the RPE65 gene, according to the human genome project working draft at http://genome.cse.ucsc.edu (freeze June 2002).

Amplification reactions were done with $50 \mathrm{ng}$ genomic DNA, 6 pmol of each primer, $200 \mu \mathrm{M}$ of dATP, dTTP, dGTP, and dCTP, 2 pmol $\alpha\left[{ }^{32} \mathrm{P}\right]$-dCTP. $1 \times$ SuperTaq buffer $(10 \mathrm{mM}$ Tris-HCl, pH 9.0; $50 \mathrm{mM} \mathrm{KCl} ; 1.5 \mathrm{mM} \mathrm{MgCl}_{2} ; 0.1 \%$ (wt/vol) Triton X-100; $0.01 \%$ (wt/vol) gelatine), and $0.1 \mathrm{U}$ Taq DNA polymerase (Invitrogen). Cycling parameters consisted of $94^{\circ} \mathrm{C}$ for $4 \mathrm{~min}$, followed by 30 cycles of $92^{\circ} \mathrm{C}$ for $1 \mathrm{~min}, 55^{\circ} \mathrm{C}$ for $2 \mathrm{~min}, 72^{\circ} \mathrm{C}$ for $1 \mathrm{~min}$, and a final extension of $6 \mathrm{~min}$ at $72^{\circ} \mathrm{C}$. Polymerase chain reaction (PCR) products were separated on a $6.6 \%$ denaturing polyacrylamide gel (acrylamide: $\mathrm{N}, \mathrm{N}^{\prime}$-methylene-bisacrylamide 19:1), containing $100 \mathrm{mM}$ Tris-borate, 2 mM EDTA pH 8.3, and 8.3 M Urea. After electrophoresis and drying of the gels the bands were visualised by overnight exposure on an X-Omat AR film.

After strong evidence of involvement of the RPE65 gene was obtained, we analysed the nucleotide sequence of the 14 exons of the RPE65 gene in genomic DNA of one healthy individual and three probands (BII-5, GII-1, and HII-1). We slightly adapted the PCR conditions described by Marlhens and coworkers. ${ }^{13}$ The PCR buffer contained $3 \mathrm{mM} \mathrm{MgCl}_{2}$ and we employed the following PCR cycling temperatures: $30 \mathrm{~s}$ at $94^{\circ} \mathrm{C}, 30 \mathrm{~s}$ at $56^{\circ} \mathrm{C}$ (exons 4 to 10 ) or $60^{\circ} \mathrm{C}$ (exons 1 to 3 and 11 to 14 ), and $1 \mathrm{~min}$ at $72^{\circ} \mathrm{C}$ ( 30 cycles). Cycle sequencing was done by using the same gene specific PCR primers ${ }^{13}$ to amplify the 14 exons and flanking introns sequences of the RPE65 gene. The PCR products were purified by using the Millipore purification system and analysed on ABI3730 or ABI3100 DNA analysers. Automatic analysis was done by ABI basecaller.

The presence of the $1156 \mathrm{~T} \rightarrow \mathrm{C} \quad$ (Tyr368His) founder mutation was tested in 96 healthy controls from the genetic isolate after isolating DNA from buccal swabs. Mucous membrane cells were collected by firmly brushing the inside of the cheek, after which $600 \mu \mathrm{l}$ of $50 \mathrm{mM} \mathrm{NaOH}$ were added and the samples were heated for $5 \mathrm{~min}$ at $95^{\circ} \mathrm{C}$. Buccal swabs were removed and $60 \mu \mathrm{l}$ Tris $\mathrm{pH} 8.0$ was added. After centrifugation at $10000 \times g$ for $10 \mathrm{~min}$, the supernatant was collected and used for PCR of exon 10 of the RPE65 gene and subsequent restriction fragment analysis using NlaIII.

Eventually, the same analysis was used to test a panel of 94 healthy controls from the Netherlands, 75 Dutch patients with autosomal recessive or isolated retinitis pigmentosa, and 86 patients with LCA (15 from the Netherlands, 18 from Germany, two from the USA, and 51 from Canada).

\section{RESULTS}

\section{Clinical evaluation}

The relevant clinical data are summarised in table 1. None of the 14 newborns followed objects or made eye contact, leading their parents to suspect visual impairment within the first three months of life. Most of the children were seen by an ophthalmologist within their first year. All experienced night blindness. Nine children went to regular schools while the others attended schools for the visually impaired. Two of the children (AII-2, HII-5) were considered to have psycho- motor retardation with an autistic-like contact disorder. One patient (BII-5) underwent surgery because of polydactyly.

A wide range of visual acuities was observed at the first examination. On follow up visual acuity varied: in nine patients (AII-2, AII-3, BII-5, CII-2, DII-1, EII-1, FII-2, GII-1 JII-2) it remained relatively stable or seemed to improve, whereas in four (HII-1, HII-2, HII-5, KII-6) it deteriorated (table 1). All but two children showed early onset nystagmus or developed nystagmus within the first six years of life. Eight patients showed a mild torticollis. None of the patients had photophobia; on the contrary, all children adored bright light. Two patients had moderate hypermetropia, one of whom (BII-5) had a father and an older sister who were also hypermetropic but did not have a retinal disorder. The other hypermetropic individual (HII-5) had two affected siblings who were near emmetropic. Three patients had moderate myopia (DII-1, JII-2, KII-6). Six children had strabismus, which led to an amblyopic eye in two (table 1). Pupillary reactions were normal and symmetrical in all. None of the patients had cataract.

Early fundoscopy was either normal or showed relative hypopigmentation or subtle changes in the retinal pigment epithelium. Macular reflexes were still present in all patients, while foveal reflexes were present in half the affected individuals. At the most recent examination retinal vessels were moderately or severely attenuated and the optic discs were pale in all patients. In five patients the periphery appeared hypopigmented. All patients had subtle subretinal pigmentary changes. No intraretinal bone spicules were seen. Macular reflexes were still present later in life, whereas the foveal reflexes disappeared in all but one patient (table 1).

Seven of the 14 patients were unable to perform colour vision tests. In the other seven patients colour vision was severely disturbed and had an overall tendency to the tritan axe (blue-yellow axe). Tübinger visual field assessment was done in 13 patients. Though visual field defects were slightly progressive over the years, the peripheral fields remained relatively stable in 10 patients. In only three was there marked deterioration. Dark adaptation tests were done in three patients and showed monophasic curves with a markedly increased rod and cone segment. ERGs were done within the first three years of life in 12 patients. In seven no responses were detected. In four patients, significantly reduced photopic responses were measured, with absent scotopic responses. In only one patient (HII-5) were both scotopic and photopic responses recorded (table 1).

\section{Genealogy}

Genealogical studies showed that all 10 families were related through at least one and in most cases several common ancestors (fig 1). Some patients were first degree cousins (for example, patients from families $\mathrm{B}$ and $\mathrm{C}$; patients from families D and E); others were only connected through a common ancestor living in the 18th century eight generations ago (for example, families $F$ and $G$ ). We therefore reasoned that the retinal dystrophy in the 10 families was most probably caused by homozygosity-by-descent of one or a small number of autosomal recessive mutations.

\section{Molecular genetic analysis}

The phenotypes described above suggested the involvement of the RPE65 gene, as previous studies have implicated this gene in patients with LCA and early onset severe rod-cone dystrophy quite similar to the clinical presentation described in patients in this study. ${ }^{14-16}$ To test this hypothesis, we undertook linkage analysis employing the DNA marker DiS2803 located only $2.5 \mathrm{~kb}$ proximal of the RPE65 gene. Eight of 10 families were partially or fully informative (fig 1). All affected individuals except patient GII- 1 are homozygous for D1S2803 allele b. Given that allele b has a frequency of 
Table 1 Ophthalmological data for 13 patients with a homozygous Tyr368His RPE65 mutation, and one patient (GII-1) with compound heterozygous RPE65 mutations

\begin{tabular}{|c|c|c|c|c|c|c|c|c|c|}
\hline \multirow[b]{2}{*}{ Individual } & \multicolumn{2}{|c|}{$\begin{array}{l}\text { First visual acuity } \\
\text { (age) }\end{array}$} & \multirow[b]{2}{*}{ First fundoscopy } & \multicolumn{2}{|c|}{$\begin{array}{l}\text { Recent visual acuity } \\
\text { (age) }\end{array}$} & \multirow[b]{2}{*}{ Recent fundoscopy } & \multicolumn{2}{|c|}{$\begin{array}{l}\text { Objective refraction } \\
\text { spherical equivalent }\end{array}$} & \multirow{2}{*}{ Electrophysiology (age) } \\
\hline & $\overline{\mathrm{RE}}$ & LE & & RE & LE & & $\mathrm{RE}$ & LE & \\
\hline All-2 & \multicolumn{2}{|c|}{$\begin{array}{l}\text { BE: } 20 / 60 \\
(4 y)\end{array}$} & Normal & $\begin{array}{l}20 / 800 \\
(15 y)^{*}\end{array}$ & $20 / 60$ & \multirow{2}{*}{$\begin{array}{l}\text { Severely attenuated } \\
\text { vessels; MR+; peripheral } \\
\text { pigmentary alterations } \\
\text { Optic disc pallor, } \\
\text { moderately attenuated } \\
\text { vessels; MR+; peripheral } \\
\text { pigment alterations }\end{array}$} & -0.25 & -0.25 & $\begin{array}{l}\text { SR and PR: non-recordable } \\
(1 \mathrm{y})\end{array}$ \\
\hline All-3 & $\begin{array}{l}20 / 60 \\
(9 y)\end{array}$ & $20 / 100$ & Normal & $\begin{array}{l}20 / 50 \\
(17 \mathrm{y})\end{array}$ & $20 / 80$ & & Plano & -1.00 & $\begin{array}{l}\text { SR: non-recordable; PR: } \\
\text { significantly reduced ( } 2 \text { y) }\end{array}$ \\
\hline Bll-5 & $\begin{array}{l}20 / 200 \\
(4 \mathrm{y})\end{array}$ & $20 / 200$ & Normal & $\begin{array}{l}20 / 200 \\
(15 \mathrm{y})\end{array}$ & $20 / 125$ & $\begin{array}{l}\text { Optic disc pallor; } \\
\text { moderately attenuated } \\
\text { vessels; macular } \\
\text { pigmentation; mid- } \\
\text { peripheral pigment } \\
\text { alterations }\end{array}$ & +2.75 & +3.50 & \\
\hline CII-2 & $\begin{array}{l}20 / 250 \\
(3 y)\end{array}$ & $20 / 200$ & $\begin{array}{l}\text { Subtle RPE changes, } \\
\text { MR+, FR+ }\end{array}$ & $\begin{array}{l}20 / 150 \\
(9 y)\end{array}$ & $20 / 100$ & $\begin{array}{l}\text { Optic disc pallor; } \\
\text { moderately attenuated } \\
\text { vessels; } M R+; F R+; \\
\text { mottled pigmentation } \\
\text { in periphery }\end{array}$ & Plano & Plano & $\begin{array}{l}\text { SR and PR: non-recordable } \\
(3 \mathrm{y})\end{array}$ \\
\hline DII-1 & $\begin{array}{l}\mathrm{HM} 2 \mathrm{~m} \\
(6 \mathrm{y})\end{array}$ & $\mathrm{HM} 2 \mathrm{~m}$ & $\begin{array}{l}\text { Hypopigmented } \\
\text { fundus; MR+; FR- }\end{array}$ & $\begin{array}{l}20 / 400 \\
(21 \mathrm{y})\end{array}$ & $20 / 400$ & $\begin{array}{l}\text { Optic disc pallor; } \\
\text { attenuated vessels; } \\
\text { hypopigmentated fundus } \\
\text { with peripheral } \\
\text { pigmentations }\end{array}$ & -3.50 & -2.50 & $\begin{array}{l}\text { SR and PR: non-recordable } \\
(3 \mathrm{y})\end{array}$ \\
\hline Ell-1 & $\begin{array}{l}20 / 60 \\
(6 y)\end{array}$ & $20 / 80$ & Normal & $\begin{array}{l}20 / 100 \\
(8 y)\end{array}$ & $20 / 80$ & $\begin{array}{l}\text { Moderately attenuated } \\
\text { vessels; MR+; RPE atrophy }\end{array}$ & -0.50 & Plano & $\begin{array}{l}\text { SR and PR: non-recordable } \\
(1 \text { y) }\end{array}$ \\
\hline Ell-4 & & & & & & & & & $\begin{array}{l}\text { SR and PR: non-recordable } \\
\text { (1 y) }\end{array}$ \\
\hline FII-2 & $\begin{array}{l}20 / 300 \\
(1 \mathrm{y})\end{array}$ & $20 / 200$ & Subtle RPE changes & $\begin{array}{l}20 / 200 \\
(8 y)\end{array}$ & $20 / 200$ & $\begin{array}{l}\text { Optic disc pallor; } \\
\text { attenuated vessels; } \\
\text { irregular pigment } \\
\text { alterations }\end{array}$ & Plano & Plano & \\
\hline GII-1 & BE: $20 / 20$ & $00(1$ y) & $\begin{array}{l}\text { Hypopigmentated } \\
\text { fundus; MR+; FR- }\end{array}$ & $\begin{array}{l}\text { BE: } 20 / 20 \\
(2 y)\end{array}$ & & $\begin{array}{l}\text { Optic disc pallor; mildly } \\
\text { attenuated vessels; MR+; } \\
\text { hypopigmentated mid- } \\
\text { periphery }\end{array}$ & Plano & Plano & $\begin{array}{l}\text { SR and PR: non-recordable } \\
(1 \text { y) }\end{array}$ \\
\hline HII-1 & $\begin{array}{l}20 / 50 \\
(4 \mathrm{y})\end{array}$ & $20 / 150$ & $\begin{array}{l}\text { Subtle RPE changes; } \\
\text { MR+; FR+ }\end{array}$ & $\begin{array}{l}20 / 60 \\
(19 y)\end{array}$ & $20 / 200$ & $\begin{array}{l}\text { Optic disc pallor; mildly } \\
\text { attenuated vessels, MR+, } \\
\text { hypopigmentated fundus, } \\
\text { mottled pigmentation in } \\
\text { periphery }\end{array}$ & +0.50 & +0.50 & $\begin{array}{l}\text { SR: non-recordable; PR: } \\
\text { significantly reduced (4 y) }\end{array}$ \\
\hline HII-2 & $\begin{array}{l}20 / 300 \\
(4 \mathrm{y})\end{array}$ & $20 / 300$ & $\begin{array}{l}\text { Subtle RPE changes; } \\
\text { MR+; FR- }\end{array}$ & $\begin{array}{l}20 / 600 \\
(19 y)\end{array}$ & $\mathrm{HM} 1 \mathrm{~m}^{*}$ & $\begin{array}{l}\text { Optic disc pallor; mildly } \\
\text { attenuated vessels; MR+; } \\
\text { hypopigmentated fundus, } \\
\text { mottled pigmentation in } \\
\text { periphery }\end{array}$ & +0.50 & +0.50 & $\begin{array}{l}\text { SR: non-recordable; PR: } \\
\text { significantly reduced ( } 2 \text { y) }\end{array}$ \\
\hline HII-5 & $\begin{array}{l}20 / 150 \\
(2 y)\end{array}$ & $20 / 150$ & $\begin{array}{l}\text { Subtle RPE changes; } \\
\text { MR+; FR- }\end{array}$ & $\begin{array}{l}20 / 250 \\
(10 y)\end{array}$ & $20 / 300$ & $\begin{array}{l}\text { Optic disc pallor; } \\
\text { moderately attenuated } \\
\text { vessels; MR+; mottled } \\
\text { pigmentation in periphery }\end{array}$ & +4.25 & +4.25 & $\begin{array}{l}\text { SR and PR: significantly } \\
\text { reduced (1 y) }\end{array}$ \\
\hline JII-2 & $\begin{array}{l}20 / 100 \\
(4 \mathrm{y})\end{array}$ & $20 / 100$ & $\begin{array}{l}\text { Hypopigmentated } \\
\text { fundus; MR+; FR- }\end{array}$ & $\begin{array}{l}20 / 50 \\
(12 y)\end{array}$ & $20 / 40$ & $\begin{array}{l}\text { Moderately attenuated } \\
\text { vessels; MR+; mid- } \\
\text { peripheral pigmentary } \\
\text { changes }\end{array}$ & -4.50 & -4.50 & $\begin{array}{l}\text { SR non-recordable; PR: } \\
\text { present (1 y) }\end{array}$ \\
\hline KII-6 & $\begin{array}{l}20 / 60 \\
(6 y)\end{array}$ & $20 / 80$ & $\begin{array}{l}\text { Subtle RPE changes; } \\
\text { MR+; FR- }\end{array}$ & $\begin{array}{l}20 / 150 \\
(10 y)\end{array}$ & $20 / 150$ & $\begin{array}{l}\text { Moderately attenuated } \\
\text { vessels; MR+; } \\
\text { hypopigmentated } \\
\text { periphery; RPE } \\
\text { granulated, some } \\
\text { peripheral pigmentations }\end{array}$ & -1.00 & -2.50 & $\begin{array}{l}\text { SR and PR: non-recordable } \\
(0.5 \mathrm{y})\end{array}$ \\
\hline
\end{tabular}

*Amblyopia

$B E$, both eyes; $D$, development of visual acuity; $F R$, foveal reflex; $H M$, hand movements; $L E$, left eye; $m$, month; $M R$, macular reflex; PR, photopic responses; $R E$, right eye; RPE, retinal pigment epithelium; SR, scotopic responses; $y$, year.

0.32 (http://gdbwww.gdb.org) the likelihood that it occurs in 19 of 20 alleles from the probands of the nuclear families is $(0.32)^{19} \times 0.68=8.6^{-11}$. This calculation strongly suggests the presence of a homozygous founder mutation in these patients. Moreover, analysis of marker D1S2895, situated 3 CM proximal to the RPE65 gene, also revealed homozygosity of one allele in five of eight informative families (data not shown).

Subsequently, we analysed the nucleotide sequence of the 14 protein coding exons of the RPE65 gene in three probands
(BII-5, HII-1, and GII-1) and one control DNA sample. We identified a homozygous $1156 \mathrm{~T} \rightarrow \mathrm{C}$ nucleotide change (Tyr368His) in patients BII-5 and HII-1. Patient GII-1 was found to be compound heterozygous for the $1156 \mathrm{~T} \rightarrow \mathrm{C}$ nucleotide change and a splice site mutation in intron 1 $($ IVS $1+5 \mathrm{~g} \rightarrow \mathrm{a})$ (data not shown).

We analysed the segregation of the exon 10 mutation by RFLP analysis as the $1156 \mathrm{~T} \rightarrow \mathrm{C}$ change introduces a NlaIII restriction site. The normal PCR product of exon 10 contains one NlaIII site resulting in restriction fragments of 41 and 205 


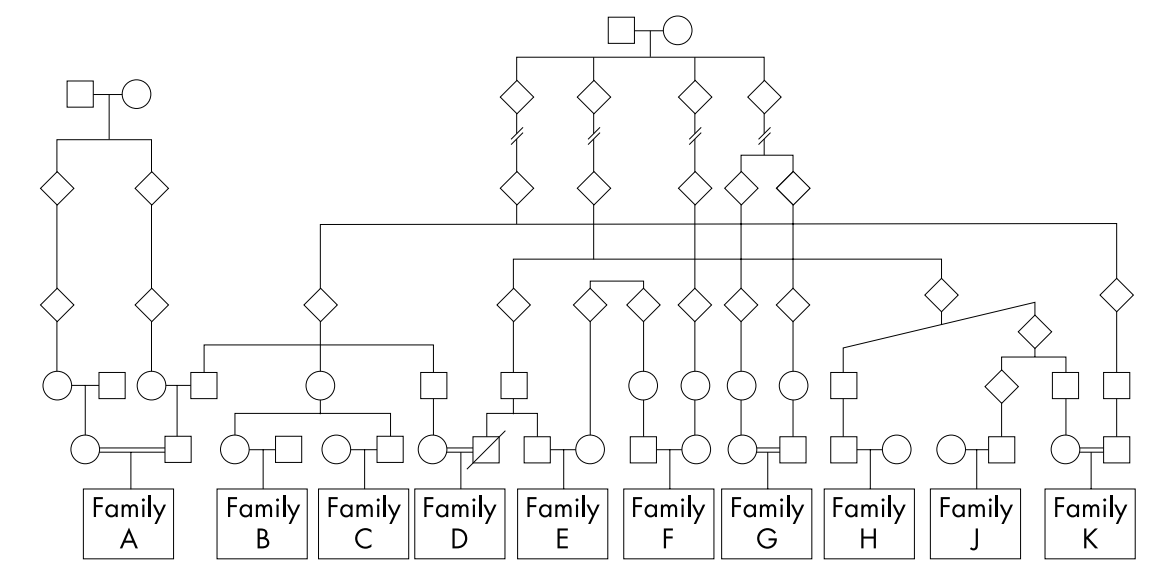

Figure 1 Anonymised and simplified pedigree structure of part of the genetic isolate (top) and D1S2803 marker alleles in the families with early onset retinal dystrophy (bottom). The individuals in the oldest generation were born in the second half of the 18th century. Double bars reflect known consanguinity. Numbers in the circles in the youngest generation indicate the number of siblings who share the same alleles for marker D1S2803. All affected individuals except GII-1 are homozygous for allele $b$, suggesting the presence of a founder mutation in the affected individuals through

homozygosity-by-descent. Patient GII-1 is heterozygous for marker D1S2803, suggesting the presence of two different

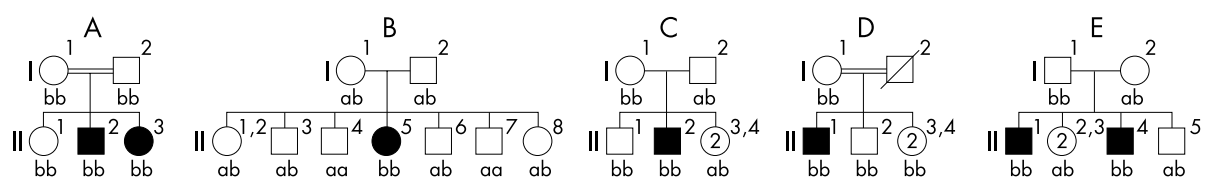
RPE65 mutations. $\diamond$, unaffected male or female; $\square$, unaffected male; $\bigcirc$, unaffected female; $\mathbf{n}$, affected male; (2), affected female.
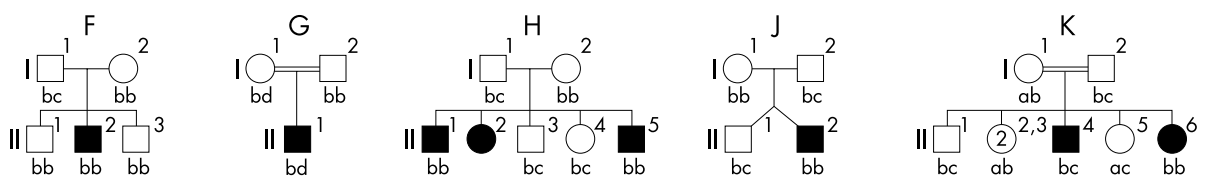

bp; a mutant allele is cut into 41, 85, and 120 bps. As illustrated for family B, patient BII-5 was indeed homozygous for the mutant restriction pattern (fig 2). Five healthy siblings were heterozygous for this mutation and two unaffected siblings did not carry a mutant allele. NlaIII RFLP analysis of the 10 families showed that all patients except GII- 1 were homozygous for the $1156 \mathrm{~T} \rightarrow \mathrm{C}$ nucleotide change and that all parents except GI-1 were heterozygous carriers of this mutation. GI- 1 instead carried the IVS $1+5 \mathrm{~g} \rightarrow \mathrm{a}$ mutation. Among 25 unaffected siblings tested, 17 were heterozygous for the Tyr368His mutation and eight did not carry this mutation. No other mutations or polymorphisms were found in the three patients and one control DNA sample analysed.

Using the NlaIII RFLP analysis three of 96 healthy controls from the genetic isolate were shown to carry the Tyr368His founder mutation heterozygously. We also investigated the frequency of this founder mutation in a panel of 86 patients with LCA from different white populations, 75 patients with
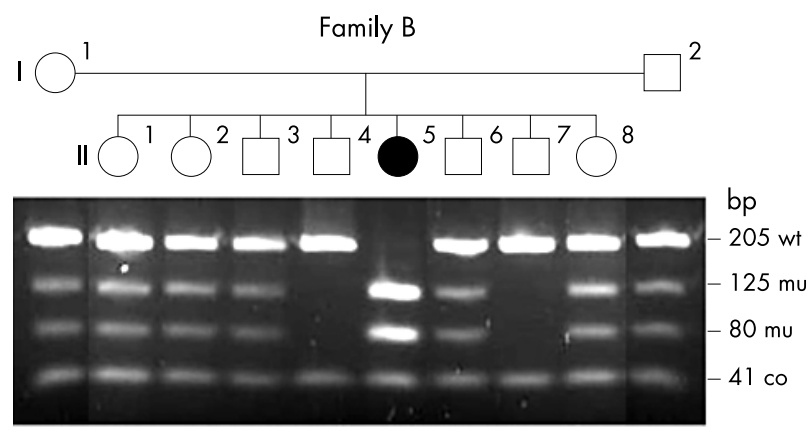

Figure 2 Restriction fragment length polymorphism based cosegregation analysis of RPE65 Tyr368His mutation in family $\mathrm{B}$ of the genetic isolate. Nlalll cuts the $246 \mathrm{bp} \mathrm{PCR} \mathrm{product} \mathrm{in} \mathrm{fragments} \mathrm{of} 41$ and 205 bp in wild type alleles and in 41,80 , and 125 bp in mutant alleles. Five non-affected siblings are heterozygous carriers of the Tyr368His mutation; two carry wild type alleles. Wt, wild type; mu, mutant; co, constant. Siblings are not depicted in order of age to preserve anonymity. autosomal recessive or isolated retinitis pigmentosa from the Netherlands, and 94 healthy controls from the Netherlands. The Tyr368His mutation was not found in the random control group or in the LCA cohort but was found heterozygously in one Dutch patient with retinitis pigmentosa and early onset visual loss.

\section{DISCUSSION}

We found 14 patients with a congenital retinal dystrophy belonging to 10 related families from a former genetic isolate in the Netherlands. The age of onset of the retinal dystrophy suggests LCA, but several characteristics of the disease-for example, visual acuity, visual fields, and night blindnessstrongly support the diagnosis of early onset retinitis pigmentosa. We therefore classify the phenotype of our patients as an early onset severe retinal dystrophy. Based on a comparison of the phenotypes observed in patients of our pedigree with previous genotype-phenotype studies, ${ }^{14}{ }^{16}$ we hypothesized that the RPE65 gene represented a good candidate gene. Linkage analysis of a highly polymorphic marker located very near the RPE65 gene revealed homozygosity-by-descent in nine of 10 families. We found homozygosity for a Tyr368His mutation in nine families, and compound heterozygosity of the Tyr 368 His and IVS $1+5 \mathrm{~g} \rightarrow \mathrm{a}$ mutations in one patient of the other family. The Tyr368His mutation has most probably been inherited from a common ancestor of all 10 families born in the 18th century or before. The IVS $1+5 \mathrm{~g} \rightarrow$ a mutation is the most frequently encountered LCA associated RPE65 mutation. ${ }^{5}$

Both RPE65 variants described above have been found previously in patients with similar phenotypes and were not found in 50 random control individuals from the general population. Moreover, the Tyr368 residue is conserved among human, bovine, canine, rat, chicken, and salamander species. ${ }^{17}$

Our results clearly show that a homozygous Tyr368His mutation in the RPE65 gene can be associated with a large variability in visual acuity. Moreover, over a mean nine year follow up period, visual acuity either remained stable, seemed to improve slightly, or deteriorated. The observed improvement can be explained by visual and mental development 
that may influence results of visual acuity testing favourably. Within families, concordance of progression of the disease was observed. At present, six patients are over 20 years of age and have stable visual acuity. Based on our findings it is not possible to give patients with a homozygous Tyr368His mutation an accurate prediction on the progression of retinal degeneration and their future visual acuity. An explanation for the variable clinical outcome cannot be found in the different functional consequences of the various mutations. Clearly, other genetic or environmental factors influence visual acuity and its progression. No other patients have been described with a homozygous RPE65 Tyr368His mutation. Patients who are compound heterozygous for this mutation and an Arg9lTrp mutation showed a more severe disease course..$^{16} 18$

In a previously identified patient with the same compound heterozygous mutations as patient GII-1, the age of onset was five years, with a visual acuity of 20/100 (both eyes) and three diopters of hypermetropic correction, ${ }^{18}$ whereas our patient was visually impaired since birth, had a visual acuity of 20/200, and was emmetropic by the age of three years. Again, knowledge of the mutations seems of no predictive value for disease course. On initial examination patients had normal fundi or mild changes, whereas eventually all fundi showed severe and more prominent changes, similar to the development as described by Lorenz and co-workers. ${ }^{16}$

Four patients described by Lorenz et al and two described by Felius et al were hypermetropic, as were nine of 12 patients with RPE65 mutations described by Lotery et al. ${ }^{16}{ }^{18}{ }^{19}$ Within our group of 13 patients with a homozygous Tyr368His mutation only two were hypermetropic. One hypermetropic patient had two unaffected relatives who were hypermetropic, suggesting that other genetic factors were involved. The other patient had two affected siblings who were near emmetropic. Thus the homozygous Tyr368His mutation, in contrast to other combinations of RPE65 mutations, is not associated with hypermetropia.

In a study of the same population 43 years ago, SchappertKimmijser and coworkers ascertained 13 LCA patients in eight families. ${ }^{11}$ It can be predicted that most if not all of these patients carried the Tyr368His founder mutation. Assuming that half of the patients seen by SchappertKimmijser and co-workers are still alive and as we have not investigated this population in depth, a conservative estimate would be that there are 25 patients with early onset severe retinal dystrophy in the current population (consisting of 16500 people) carrying the Tyr368His founder mutation homozygously. Assuming heterozygosity of this mutation in $1 / 660$ individuals, we deduced a carrier frequency of $\sim 1$ in 13. Analysis of 96 healthy individuals from the genetic isolate yielded a Tyr368His carrier frequency of 3.1\% (95\% confidence interval, $-0.4 \%$ to $-6.6 \%)$. Based on the observed carrier frequency of the Tyr368His founder mutation in this former genetic isolate, patients and heterozygous carriers with partners from this population have a risk of $\sim 1 / 56$ and $\sim 1 / 112$, respectively, that anyone of their children will develop early onset severe retinal dystrophy.

RPE65 has a crucial, but as yet not fully understood, role in the isomerisation of all-trans-retinal to 11-cis-retinol in the retinal pigment epithelium. ${ }^{20}{ }^{21}$ In RPE65 deficient mice and dogs, pharmacological and somatic gene therapy based treatments, respectively, were successful..$^{22}$ It is clear that further assessments of long term safety and efficacy are required for various treatment strategies and, as treatment may need to be applied very early in life, ethical aspects will have to be considered. Nevertheless, patients carrying defects in the RPE65 gene might become eligible for future clinical trials, underscoring the importance of their early clinical and molecular genetic identification.

\section{ACKNOWLEDGEMENTS}

We thank the patients, their family members, and their general practitioners for their kind cooperation, Dr E Hennekam for genealogical studies, and M F W J Ariaans, M Zonneveld, and Dr R Roepman for their assistance in several aspects of these studies. This study was supported by the "Stichting Wetenschappelijk Onderzoek het Oogziekenhuis prof dr H J Flieringa" Rotterdam (LIvdB, FPMC), Retina Netherlands (LIvdB, FPMC), and the Canadian Foundation Fighting Blindness (Toronto, Ontario; RKK, FPMC).

\section{Authors' affiliations \\ S Yzer, LI van den Born, The Rotterdam Eye Hospital, Rotterdam, Netherlands \\ S Yzer, B van den Helm, H G Brunner, F P M Cremers, Department of Human Genetics, University Medical Centre Nijmegen, Nijmegen, Netherlands \\ J Schuil, M M van Genderen, F N Boonstra, Institute for the Visually Handicapped "Bartimeus", Zeist, Netherlands \\ H Y Kroes, Department of Medical Genetics, University Medical Centre Utrecht, Netherlands \\ R K Koenekoop, The McGill Ocular Genetics Laboratory, Montreal Children's Hospital Research Institute, McGill University Montreal, Canada}

Correspondence to: Dr F P M Cremers, Department of Human Genetics, University Medical Centre Nijmegen, PO Box 9101, 6500 HB Nijmegen, Netherlands; f.cremers@antrg.umcn.nl

\section{REFERENCES}

1 Heckenlively JR. Retinitis pigmentosa. Philadelphia: Lippincott, 1988.

2 Lambert SR, Taylor D, Kriss A. The infant with nystagmus, normal appearing fundi, but an abnormal ERG. Surv Ophthalmol 1989:34:173-86.

3 Foxman SG, Heckenlively JR, Bateman JB, et al. Classification of congenital and early onset retinitis pigmentosa. Arch Ophthalmol 1985;103:1502-6.

4 Heckenlively JR, Yoser SL, Friedman LH, et al. Clinical findings and common symptoms in retinitis pigmentosa. Am J Ophthalmol 1988;105:504-11.

5 Cremers FPM, van den Hurk JAJM, den Hollander Al. Molecular genetics of Leber congenital amaurosis. Hum Mol Genet 2002;11:1169-76.

6 Rivolta C, Sharon D, DeAngelis MM, et al. Retinitis pigmentosa and allied diseases: numerous diseases, genes, and inheritance patterns. Hum Mol Genet 2002;11:1219-27.

7 Taschner PEM, Vos de N, Post JG, et al. Carrier detection of Batten disease (juvenile neuronal ceroid-lipofuscinosis). Am J Med Genet 1995;57:333-7.

8 Defesche JC, van Diermen DE, Hayden MR, et al. Origin and migration of an Afrikaner founder mutation FHAfrikaner-2 (V408M) causing familial hypercholesterolemia. Gene Geogr 1996;10:1-10.

9 van Soest S, van den Born LI, Gal A, et al. Assignment of a gene for autosomal recessive retinitis pigmentosa (RP12) to chromosome lq31-q32.1 in a inbred and genetically heterogeneous disease population. Genomics 1994:22:499-504.

10 den Hollander Al, ten Brink JB, de Kok YJM, et al. Mutations in a human homologue of Drosophila crumbs cause retinitis pigmentosa (RP12). Nat Genet 1999;23:217-21.

11 Schappert-Kimmiiser J, Henkes HE, van den Bosch J. Amaurosis congenita (Leber). Arch Ophthalmol 1959:61:211-18.

12 Miller SA, Dykes DD, Polesky HF. A simple salting out procedure for extracting DNA from human nucleated cells. Nucleic Acids Res 1988;16:1215.

13 Marlhens F, Bareil C, Griffoin J-M, et al. Mutations in RPE65 cause Leber's congenital amaurosis. Nat Genet 1997;17:139-41.

14 Perrault I, Rozet J-M, Gerber S, et al. Leber congenital amaurosis. Mol Genet Metab 1999;68:200-8

15 Perrault I, Rozet JM, Ghazi I, et al. Different functional outcome of RetGC1 and RPE65 gene mutations in Leber congenital amaurosis. Am J Hum Genet 1999:64:1225-8.

16 Lorenz B, Gyurus P, Preising M, et al. Early-onset severe rod-cone dystrophy in young children with RPE65 mutations. Invest Ophthalmol Vis Sci 2000;41:2735-42.

17 Thompson DA, Gyürüs P, Fleischer LL, et al. Genetics and phenotypes of RPE65 mutations in inherited retinal degeneration. Invest Ophthalmol Vis Sci 2000;41:4293-9.

18 Felius J, Thompson DA, Khan NW, et al. Clinical course and visual function in a family with mutations in the RPE65 gene. Arch Ophthalmol 2002;120:55-61.

19 Lotery AJ, Namperumalsamy P, Jacobson SG, et al. Mutation analysis of 3 genes in patients with Leber congenital amaurosis. Arch Ophthalmol 2000;118:538-43

20 Redmond TM, Yu S, Lee E, et al. Rpe65 is necessary for production of 11-cisvitamin A in the retinal visual cycle. Nat Genet 1998;20:344-51.

21 Saari JC. The sights along route 65. Nat Genet 2001;29:8-9.

22 Van Hooser JP, Aleman TS, He YG, et al. Rapid restoration of visual pigment and function with oral retinoid in a mouse model of childhood blindness. Proc Natl Acad Sci USA 2000:97:8623-8.

23 Acland GM, Aguirre GD, Ray J, et al. Gene therapy restores vision in a canine model of childhood blindness. Nat Genet 2001;28:92-5. 